Article

\title{
Risk Assessment of Two Insecticides on Encarsia formosa, Parasitoid of Whitefly Bemisia tabaci
}

\author{
Zhan He ${ }^{1}$, Yuan Liu ${ }^{1}$, Lei Wang ${ }^{2}$, Qiu Guo ${ }^{2}$, Shaukat Ali ${ }^{1}$, Xiao-Sheng Chen ${ }^{1,3, *}$ \\ and Bao-Li Qiu ${ }^{1,2, *}$
}

1 Key Laboratory of Bio-Pesticide Innovation and Application, South China Agricultural University, No. 483, Wushan Rd., Tianhe, Guangzhou 510640, China; happy-hezhan@163.com (Z.H.);

LYuan@stu.scau.edu.cn (Y.L.); aliscau@scau.edu.cn (S.A.)

2 Engineering Technology Research Center of Agricultural Pest Biocontrol, South China Agricultural University, No. 483, Wushan Rd., Tianhe, Guangzhou 510640, China; wangleiscau@163.com (L.W.); guo_qiu@163.com (Q.G.)

3 College of Forestry and Landscape Architecture, South China Agricultural University, No. 483, Wushan Rd., Tianhe, Guangzhou 510640, China

* Correspondence: xshchen@scau.edu.cn (X.-S.C.); baileyqiu@scau.edu.cn (B.-L.Q.); Tel.: +86-020-85283717 (B.-L.Q.)

Received: 13 July 2018; Accepted: 5 September 2018; Published: 11 September 2018

check for updates

\begin{abstract}
The assessment of acute toxicity to insect natural enemies is very important for insecticide selection used within integrated pest management (IPM). The acute toxicity of abamectin and imidacloprid against Encarsia formosa, a parasitoid of Bemisia tabaci, was investigated. Abamectin had a high toxicity risk to $E$. formosa, while imidacloprid showed a medium toxicity risk. When treated with the lethal concentration $30\left(\mathrm{LC}_{30}\right)$ of abamectin, the dwelling time of E. formosa in B. tabaci infested-plant-area (IPA) was significantly lower than in non-infested plant areas (non-IPA). In addition, the frequency of $E$. formosa entering into the two areas was not significantly different in the $\mathrm{LC}_{10}$ and $\mathrm{LC}_{30}$ treatments. Within the IPA, $\mathrm{LC}_{10}$, and $\mathrm{LC}_{30}$ treatments decreased the dwelling time and entering frequency of parasitoid significantly. For imidacloprid treatments, E. formosa stayed a longer time in the non-IPA than in the IPA when treated with $\mathrm{LC}_{30}$. The frequency of $E$. formosa entering into the two areas was only slightly different in the $\mathrm{LC}_{1}, \mathrm{LC}_{10}$, and $\mathrm{LC}_{30}$ treatments. Within the IPA, $\mathrm{LC}_{10}$ and $\mathrm{LC}_{30}$ treatments were significantly decreased in the dwelling time and the entering frequency of $E$. formosa. The results indicate that abamectin and imidacloprid have high or medium acute toxicity against $E$. formosa and a negative sublethal effect on its searching behaviour.
\end{abstract}

Keywords: aphelinid parasitoid; whitefly; abamectin; imidocloprid; side effect; IPM

\section{Introduction}

The whitefly Bemisia tabaci (Gennadius) (Hemiptera: Aleyrodidae) is a global agricultural pest [1,2]. This whitefly pest causes serious damage to hundreds of crops directly by sucking phloem sap, and indirectly by causing sooty mould growth via honeydew secretion and, most importantly, by the transmission of numerous plant viruses [3-6].

Pesticide application still remains the main approach for $B$. tabaci management but the overuse of chemical pesticides has resulted in strong chemical resistance outbreaks for this whitefly pest $[7,8]$. Therefore, integrated pest management (IPM) is considered a more sustainable approach for the control of $B$. tabaci and, as a key part of IPM, biological control with parasitoids plays an important role in sustainable insect pest control [9]. To date, more than 50 species of parasitoids of $B$. tabaci have been described, among which Encarsia formosa Gahan (Hymenoptera: Aphelinidae) is an important, 
dominant parasitoid species, and it has been reported as an efficient biological agent in whitefly control in many regions of the world [9-14].

Insecticide application within an IPM programme should be toxic to target pests and non-toxic to their natural enemies [15-18]. However, many insecticides that are effective against target pests are also harmful to natural enemies, reducing the effectiveness of biological control $[14,19,20]$. Therefore, it is essential to evaluate the impact of insecticides on natural enemies. The evaluation of the acute toxicity (i.e., lethal effect) can provide partial assessment concerning the potential effects of pesticides to the exposed non-target organisms [21,22], while sublethal effects of insecticides on natural enemies may ultimately cause a decrease in their efficiency as biological control agents. Therefore, to completely assess the effects of an insecticide on a natural enemy, the risk-assessment should include acute toxicity as well as sub-lethal and chronic effects [23,24]. Based on these findings, the selection of appropriate insecticides that have a less negative impact on a given specific natural enemy is critical in the development and success of IPM of invertebrate pests [25].

Insecticides including abamectin and imidacloprid have been widely used to control B. tabaci in many countries [10,26-29]. The acute toxicities and sublethal impacts of these two insecticides have been evaluated on many parasitoid natural enemies [10,22,30-33], but the negative impacts of abamectin and imidacloprid on the biology and host searching behaviour of different developmental stages of E. formosa, have been little investigated [10,14,34].

In this study, the acute toxicity of abamectin and imidacloprid to different developmental life stages of E. formosa as well as their sublethal effects on the parasitoid's host searching behaviour were assessed. The results are expected to ameliorate the sustainable control of $B$. tabaci in IPM programmes.

\section{Materials and Methods}

\subsection{Plants, Insects and Insecticides}

Seeds of cotton Gossypium hirsutum L. (Malvales: Malvaceae) Luman No. 32 were produced by the Cotton Research Center, Shandong Academy of Agricultural Sciences, Jinan, China. Healthy seedlings were cultivated within plastic pots $(\Phi 20 \mathrm{~cm})$ in screened cages and grown to approximately $30 \mathrm{~cm}$ in height before being used in experiments. The cotton plants were not exposed to any pests or pesticides. Two to three smooth and health leaves per plant were selected for experimental tests.

The tobacco whitefly, Bemisia tabaci MEAM1 (Middle East Asia Minor 1 cryptic species, formerly B biotype), was originally collected from the training farm of South China Agricultural University (SCAU), Guangzhou in 2005, and maintained on cotton plants in a separated glasshouse in SCAU under ambient conditions. The parasitoid E. formosa was first collected from Beijing Academy of Agriculture and Forestry Sciences in 2008, and the population was maintained on cotton plants with B. tabaci as the host in separated cages.

The insecticides abamectin (95\% certified purity) and imidacloprid (97\% certified purity), were obtained from Guangxi Antai Chemicals Co. Ltd., (Nanning, China). The stock solutions of both insecticides ( $1000 \mathrm{mg} / \mathrm{L}$ and $5000 \mathrm{mg} / \mathrm{L}$ respectively) were prepared by using acetone as solvent. Five different concentrations of each insecticide $(2,4,8,16,32 \mathrm{mg} / \mathrm{L}$ for abamectin and 20, 40, 80, $160,320 \mathrm{mg} / \mathrm{L}$ for imidacloprid) were prepared through serial dilutions for the toxicity tests. Double distilled water $\left(\mathrm{ddH}_{2} \mathrm{O}\right)$ was used for the dilutions and as control.

All the bioassays were carried out under controlled environmental conditions at $26 \pm 1{ }^{\circ} \mathrm{C}$, $70 \pm 10 \%$ R.H, photoperiod of 14:10 (L:D), and light intensity of 3000Lx. Artificial climate chambers (RXZ-560, Jiangnan Instrument Factory, Ningbo, China) were used for maintaining the controlled environmental conditions.

\subsection{Toxicity to Parasitoid Adults}

The toxicity of abamectin and imidacloprid to E. formosa adults was investigated by exposing adults to dry residues $[14,35]$. Glass tubes $(1.5 \mathrm{~cm}$ diameter $\times 10 \mathrm{~cm}$ length) were filled with different 
insecticide concentrations or $\mathrm{ddH}_{2} \mathrm{O}$ (control). The insecticidal solution was poured out after $10 \mathrm{~s}$ and the tubes inverted in order to dry them out. Fifteen E. formosa adult wasps (age $<24 \mathrm{~h}$ ) were then released into each tube for different time intervals (12, 24, 48, 72 and $96 \mathrm{~h}$ ). The adult wasps were supplied with $15 \%$ honey solution drops on the tube wall and the tubes were sealed with Parafilm ${ }^{\circledR}$ (Bemis Company, Inc., Neenah, WI, USA). The mortality of E. formosa adults was recorded every $12 \mathrm{~h}$. The concentrations $\mathrm{LC}_{1}, \mathrm{LC}_{10}, \mathrm{LC}_{30}$ and $\mathrm{LC}_{50}$ of both insecticides were calculated through probit analysis (see Data analysis). Each set of treatments was repeated 3 times, with a total of 45 parasitoids tested for each time period.

\subsection{Toxicity to Parasitoid Pre-Pupae and Pupae}

The toxicity of abamectin and imidacloprid to the pre-pupa and pupa of E. formosa was investigated by topically exposing the insect via the dipping method [16,36]. Approximately 40 B. tabaci female adults were released onto healthy cotton leaves inside leaf cages $(5 \mathrm{~cm}$ diameter $\times 3 \mathrm{~cm} \mathrm{height)}$ for $24 \mathrm{~h}$ oviposition, after which all the adults were removed. When the whitefly offspring developed through to 3rd instar nymphs (5-6 days after egg hatching), five E. formosa females (2 day old) were released into the leaf cage to parasitize the nymphs for a $12 \mathrm{~h}$ period and then removed. When the parasitoids had developed to pre-pupal or pupal stage, their numbers were recorded on each leaf, and unparasitized B. tabaci nymphs were removed. The individual leaves with parasitized $B$. tabaci nymphs were then immersed into different insecticide concentrations or $\mathrm{ddH}_{2} \mathrm{O}$ (control) for $10 \mathrm{~s}$, after which the plants were cultured in an artificial climate chamber until all the parasitoids either developed into adults or died. The numbers of adults emerging were recorded daily. The $\mathrm{LC}_{1}, \mathrm{LC}_{10}$, $\mathrm{LC}_{30}$ and $\mathrm{LC}_{50}$ concentrations of both pesticides were calculated through probit analysis (see Data analysis). Each set of treatments was repeated 3 times, with a total of 120 pre-pupae or pupae tested for each wasp lifestage.

A stereo microscope (SZ45-BL3, Sunny Optical Technology (Group) Co. Ltd., Ningbo, China) was used to observe the insects during the experiments.

\subsection{Sublethal Effects on Parasitoid Searching Behaviour}

A four-armed olfactometer was used for these tests [35]. The olfactometer was divided into 4 areas of equal size. Each area was connected with a flow meter, a humidifying bottle, an air filtering bottle and an odour source bottle. The air flow of each area was controlled at $120 \mathrm{~mL} / \mathrm{min}$. The four-arm was surrounded by a shade but had a light on the top of it, so that the insects can only be exposed to light from the top.

Adults of E. formosa (age $<24 \mathrm{~h}$ ) were obtained by collecting pupae on infested cotton leaves into petri dishes with honey solution (15\%) provided as food. These newly emerged adults were not exposed to whitefly hosts. Before initiating experiments, 24 h-old E. formosa adults were individually treated with sublethal concentrations, calculated from the toxicity experiments to adults, of abamectin $\left(\mathrm{LC}_{1}=0.637 \mathrm{mg} / \mathrm{mL} ; \mathrm{LC}_{10}=1.643 \mathrm{mg} / \mathrm{mL} ; \mathrm{LC}_{30}=3.262 \mathrm{mg} / \mathrm{mL}\right)$ or imidacloprid $\left(\mathrm{LC}_{1}=4.968 \mathrm{mg} / \mathrm{mL} ; \mathrm{LC}_{10}=16.470 \mathrm{mg} / \mathrm{mL} ; \mathrm{LC}_{30}=40.262 \mathrm{mg} / \mathrm{mL}\right)$ for $1 \mathrm{~h}$ by using the residual film method [14]. The control group of E. formosa adults was treated with $\mathrm{ddH}_{2} \mathrm{O}$. When the experiments began, two healthy cotton plants were placed into 2 odour source bottles named as "non-infested plant area", while cotton plants with 3rd and 4th instar B. tabaci nymphs on their leaves were placed in the other 2 odour source bottles named as "infested plant area". All the plants used in the experiments were of the same age. One individual E. formosa wasp treated as above was released into the four-armed olfactometer through the central hole. The number of times that the E. formosa wasp entered into either the non-infested plant area or infested plant area (taken as a dwelling time of more than $5 \mathrm{~s}$ ), and their final dwelling time in each area was recorded. Each parasitoid was observed for $600 \mathrm{~s}$. The four-armed olfactometer was cleaned with ethanol followed by $\mathrm{ddH}_{2} \mathrm{O}$ after every individual parasitoid test. Each treatment was repeated 3 times with 30 parasitoids tested each repetition. 


\subsection{Data Analysis}

The sublethal concentrations ( $\mathrm{LC}_{1}, \mathrm{LC}_{10}, \mathrm{LC}_{30}$ and $\left.\mathrm{LC}_{50}\right), 95 \%$ confidence intervals, relative factors and safety factors of both insecticides were calculated through linear regression. The safety of the two insecticides to E. formosa was evaluated according to "Test guidelines on environmental safety assessment for chemical pesticides" [37], and the toxicity risk grades were divided into 5 levels (Table 1) [37].

Table 1. Definition of the pesticide risk grades to insects.

\begin{tabular}{cc}
\hline Toxicity Risk Grade & Safety Factor $(\mathrm{SF})$ \\
\hline extreme high risk & $\mathrm{SF} \leq 0.05$ \\
high risk & $0.05<\mathrm{SF} \leq 0.5$ \\
medium risk & $0.5<\mathrm{SF} \leq 5$ \\
low risk & $\mathrm{SF}>5$ \\
Note: safety factor $=\mathrm{LC}_{50}(\mathrm{mg} / \mathrm{L}) /$ ield recommended concentration $(\mathrm{mg} / \mathrm{L})$.
\end{tabular}

The differences in E. formosa dwelling time, entering frequency in whitefly infested AND non-infested plant areas treated with the same lethal concentration were analyzed using $t$-test. While the differences of E. formosa dwelling time, entering frequency in the same host plant areas (whitefly infested OR non-infested plant areas) among different lethal concentrations were compared using Duncan's test SPSS 17.0 (International Business Machines Corp., Armonk, NY, USA).

\section{Results}

\subsection{Toxicity to Parasitoid Adults}

The $\mathrm{LC}_{30}$ and $\mathrm{LC}_{50}$ values of abamectin and imidacloprid to the 12, 24, 48, 72 and $96 \mathrm{~h}$ old E. formosa adults are listed in Tables 2 and 3 respectively. Results revealed that the $\mathrm{LC}_{30}$ and $\mathrm{LC}_{50}$ value of both insecticides to E. formosa adults increased with the longevity of the parasitoid, indicating the relatively higher chemical tolerance of older adult wasps than the younger adults (Tables 2 and 3).

Table 2. Toxicity of abamectin to Encarsia formosa adults.

\begin{tabular}{ccccc}
\hline Parasitoid Age (h) & $\begin{array}{c}\text { Regression Equation of } \\
\text { Toxicity }\end{array}$ & $\begin{array}{c}\text { Correlation } \\
\text { Coefficient (r) }\end{array}$ & $\begin{array}{c}\mathbf{L C}_{\mathbf{3 0}}(\mathbf{m g} / \mathrm{L}) \\
\text { (95\% Confidence Interval) }\end{array}$ & $\begin{array}{c}\text { LC } \mathbf{5 0}(\mathbf{m g} / \mathbf{L}) \\
\text { (95\% Confidence Interval) }\end{array}$ \\
\hline 12 & $\mathrm{Y}=-0.396+1.472 X$ & 0.966 & $0.818(0.255-1.456)$ & $1.857(0.891-2.771)$ \\
24 & $\mathrm{Y}=-1.829+2.541 \mathrm{X}$ & 0.928 & $3.262(0.443-5.839)$ & $5.246(1.894-11.081)$ \\
48 & $\mathrm{Y}=-1.770+2.162 X$ & 0.973 & $3.768(2.805-4.707)$ & $6.587(5.330-8.078)$ \\
72 & $\mathrm{Y}=-2.092+2.499 \mathrm{X}$ & 0.987 & $4.239(3.312-5.150)$ & $6.872(5.695-8.266)$ \\
96 & $\mathrm{Y}=-2.439+2.560 \mathrm{X}$ & 0.991 & $5.598(4.457-6.740)$ & $8.972(7.490-10.804)$ \\
\hline
\end{tabular}

Table 3. Toxicity of imidacloprid to Encarsia formosa adults.

\begin{tabular}{ccccc}
\hline Parasitoid Age (h) & $\begin{array}{c}\text { Regression Equation of } \\
\text { Toxicity }\end{array}$ & $\begin{array}{c}\text { Correlation } \\
\text { Coefficient (r) }\end{array}$ & $\begin{array}{c}\mathbf{L C}_{\mathbf{3 0}}(\mathbf{m g} / \mathbf{L}) \\
\text { (95\% Confidence Interval) }\end{array}$ & $\begin{array}{c}\mathbf{L C}_{\mathbf{5 0}}(\mathbf{m g} / \mathbf{L}) \\
\text { (95\% Confidence Interval) }\end{array}$ \\
\hline 12 & $\mathrm{Y}=-2.854+1.740 X$ & 0.976 & $21.818(12.965-30.399)$ & $43.669(31.555-56.3)$ \\
24 & $\mathrm{Y}=-3.789+2.034 X$ & 0.974 & $40.262(29.717-50.668)$ & $72.892(58.593-90.425)$ \\
48 & $\mathrm{Y}=-4.441+2.301 X$ & 0.981 & $43.818(30.749-56.726)$ & $81.296(66.387-99.827)$ \\
72 & $\mathrm{Y}=-3.392+1.747 X$ & 0.983 & $46.943(35.828-57.980)$ & $87.470(68.605-112.343)$ \\
96 & $\mathrm{Y}=-3.399+1.688 X$ & 0.986 & $50.445(35.926-65.201)$ & $103.138(80.635-135.647)$ \\
\hline
\end{tabular}

The safety factors of abamectin to E. formosa adults of different ages ranged from 0.093 to 0.449 (Table 4), falling between the toxicity limit of 0.05 to 0.5 (Table 1), while the safety factors of imidacloprid ranged from 1.311 to 3.097 (Table 4), falling between the toxicity limit of 0.5 and 5 (Table 1). The results indicate that abamectin has a high toxicity risk to adult parasitoids while imidacloprid has a medium toxicity risk to adult parasitoids. 
Table 4. The toxicity risk grade of abamectin and imidacloprid to Encarsia formosa adults.

\begin{tabular}{ccccc}
\hline Pesticide & $\begin{array}{c}\text { Parasitoid } \\
\text { Age (h) }\end{array}$ & $\begin{array}{c}\text { Field Recommended } \\
\text { Concentration }(\mathbf{m g} / \mathbf{L})\end{array}$ & Safety Factor (SF) & $\begin{array}{c}\text { Toxicity Risk } \\
\text { Grade }\end{array}$ \\
\hline \multirow{4}{*}{ abamectin } & 12 & 20 & 0.093 & high risk \\
& 24 & 20 & 0.262 & high risk \\
& 48 & 20 & 0.329 & high risk \\
& 72 & 20 & 0.344 & high risk \\
& 96 & 20 & 0.449 & high risk \\
\hline \multirow{3}{*}{ imidacloprid } & 12 & 33.3 & 1.311 & medium risk \\
& 24 & 33.3 & 2.189 & medium risk \\
& 48 & 33.3 & 2.441 & medium risk \\
\hline
\end{tabular}

\subsection{Toxicity to Parasitoid Pre-Pupae and Pupae}

Analysis of the results revealed that, the $\mathrm{LC}_{50}$ of abamectin to the pre-pupa and pupa of E. formosa was 4.395 and $4.474 \mathrm{mg} / \mathrm{L}$, while the $\mathrm{LC}_{30}$ was 3.029 and $2.524 \mathrm{mg} / \mathrm{L}$ respectively (Table 5). The safety factors calculated for pre-pupa and pupa were 0.220 and 0.224 , both of them were between 0.05 to 0.5 , which indicates a high toxicity risk to the pre-pupa and pupa of $E$. formosa according to risk grades (Table 6). By contrast, the $\mathrm{LC}_{50}$ of imidacloprid on pre-pupa and pupa were 22.211 and $30.781 \mathrm{mg} / \mathrm{L}$, respectively. The $\mathrm{LC}_{30}$ values of imidacloprid were 8.877 and $16.990 \mathrm{mg} / \mathrm{L}$ to the pre-pupa and pupa (Table 7), and the safety factors were 0.667 and 0.993 , respectively, indicating that imidacloprid has a medium toxicity risk to the pre-pupa and pupa of E. formosa (Table 6).

Table 5. Toxicity of abamectin to the pre-pupa and pupa of Encarsia formosa.

\begin{tabular}{ccccc}
\hline Parasitoid Stage & $\begin{array}{c}\text { Regression Equation of } \\
\text { Toxicity }\end{array}$ & $\begin{array}{c}\text { Correlation } \\
\text { Coefficient (r) }\end{array}$ & $\begin{array}{c}\mathbf{L C}_{\mathbf{3 0}}(\mathbf{m g} / \mathbf{L}) \\
\text { (95\% Confidence Interval) }\end{array}$ & $\begin{array}{c}\mathbf{L C}_{50}(\mathbf{m g} / \mathbf{L}) \\
\text { (95\% Confidence Interval) }\end{array}$ \\
\hline pre-pupa & $\mathrm{Y}=-2.086+3.244 X$ & 0.951 & $3.029(0.386-5.167)$ & $4.395(1.447-8.493)$ \\
pupa & $\mathrm{Y}=-1.372+2.109 X$ & 0.990 & $2.524(1.730-3.278)$ & $4.474(3.473-5.532)$ \\
\hline
\end{tabular}

Table 6. The toxicity risk grade of abamectin and imidacloprid to pre-pupa and pupa of Encarsia formosa.

\begin{tabular}{ccccc}
\hline Pesticide & Parasitoid Stage & $\begin{array}{c}\text { Field Recommended } \\
\text { Concentration }(\mathbf{m g} / \mathbf{L})\end{array}$ & Safety Factor (SF) & $\begin{array}{c}\text { Toxicity Risk } \\
\text { Grade }\end{array}$ \\
\hline \multirow{2}{*}{ abamectin } & pre-pupa & 20 & 0.220 & high risk \\
& pupa & 20 & 0.224 & high risk \\
imidacloprid & pre-pupa & 33.3 & 0.667 & medium risk \\
& pupa & 33.3 & 0.993 & medium risk \\
\hline
\end{tabular}

Table 7. Toxicity of imidacloprid to the pre-pupa and pupa of Encarsia formosa.

\begin{tabular}{ccccc}
\hline Parasitoid Stage & $\begin{array}{c}\text { Regression Equation of } \\
\text { Toxicity }\end{array}$ & $\begin{array}{c}\text { Correlation } \\
\text { Coefficient (r) }\end{array}$ & $\begin{array}{c}\mathbf{L C}_{\mathbf{3 0}}(\mathbf{m g} / \mathrm{L}) \\
\mathbf{( 9 5 \% ~ C o n f i d e n c e ~ I n t e r v a l ) ~}\end{array}$ & $\begin{array}{c}\text { LC } \mathbf{5 0} \text { (mg/L) } \\
\text { (95\% Confidence Interval) }\end{array}$ \\
\hline pre-pupa & $\mathrm{Y}=-1.773+1.317 \mathrm{X}$ & 0.931 & $8.877(2.822-15.911)$ & $22.211(11.107-33.026)$ \\
pupa & $\mathrm{Y}=-3.024+2.032 X$ & 0.951 & $16.990(1.210-32.911)$ & $30.781(6.680-54.553)$ \\
\hline
\end{tabular}

\subsection{Sublethal Effects on Parasitoid Searching Behaviour}

After treatment with $\mathrm{LC}_{1}$ and $\mathrm{LC}_{10}$ of abamectin for $1 \mathrm{~h}$ using the residual film method, E. formosa wasps did not change their choice preference, because their dwelling times in the B. tabaci infested plant areas were both significantly longer than their dwelling times in the non-infested plant areas (148.62 s vs. $69.90 \mathrm{~s}$ in $\mathrm{LC}_{1}$ experiment; $131.97 \mathrm{~s}$ vs. $86.51 \mathrm{~s}$ in $\mathrm{LC}_{10}$ experiment). However, when the concentration of abamectin increased to $\mathrm{LC}_{30}$, the dwelling time spent by E. formosa adults in the area with non-infested plants was significantly longer than the dwelling time in the area with $B$. tabaci infested plants ( $125.73 \mathrm{~s}$ vs. $76.21 \mathrm{~s}$ ), which indicates that the higher concentration of abamectin $\left(\mathrm{LC}_{30}\right)$ reduced the searching behaviour of E. formosa. When compared with the control, the dwelling time of 
E. formosa adults in B. tabaci infested plant areas of $\mathrm{LC}_{1}$ treatment had no significant difference, while the dwelling time of $\mathrm{LC}_{10}$ treatment was significantly lower and $\mathrm{LC}_{30}$ treatment was the lowest. While for the dwelling time in the non-infested plant area, no significant differences were found between the control, $\mathrm{LC}_{1}$ and $\mathrm{LC}_{10}$ treatments, but the dwelling time of $\mathrm{LC}_{30}$ treatment was significantly longer (Figure 1).

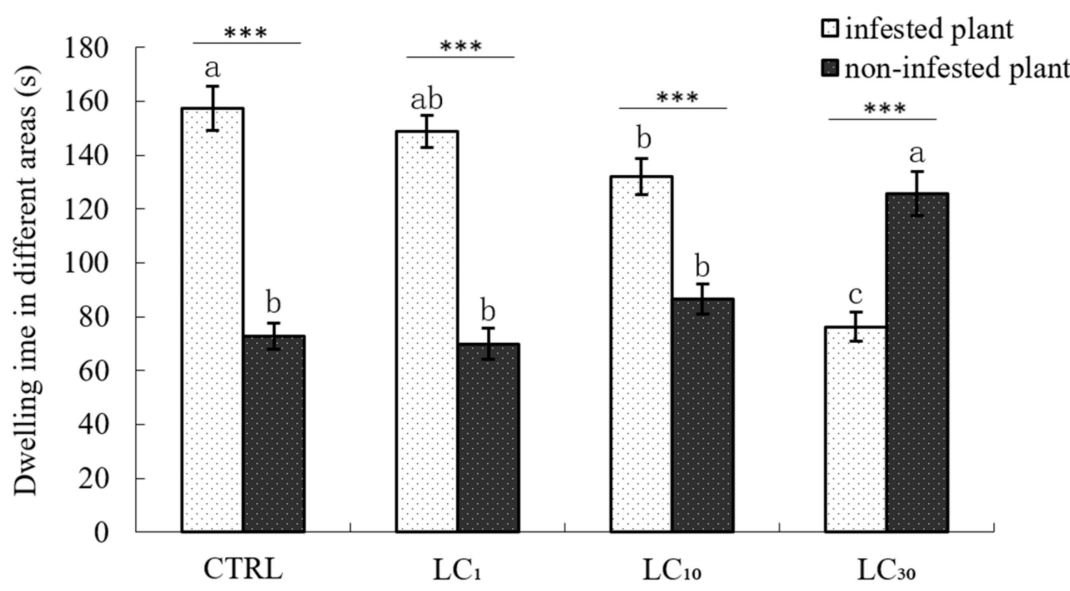

Tested abamectin concentrations

Figure 1. Dwelling time of Encarsia formosa in different plant areas treated with abamectin. Note: *** $p<0.001$ (significantly different between the two groups, $t$-test). The same letter over the bars of infested plant or non-infested plant areas indicates no significant differences between the various concentrations (Duncan's multiple range test, $\alpha<0.05$ ). The "infested plant area" means cotton plants in the four-armed olfactometer infested with 3rd or 4th instar B. tabaci nymphs, while the "non-infested plants" means healthy cotton plants without whitefly infestation in the four-armed olfactometer.

Similar to the abamectin tests, the treatment of imidacloprid $\mathrm{LC}_{1}$ and $\mathrm{LC}_{10}$ did not change the choice preference of E. formosa wasps, that is, preferring the B. tabaci infested plants over the non-infested plants (129.72 s vs. $60.64 \mathrm{~s}$ in $\mathrm{LC}_{1}$ experiment; $102.60 \mathrm{~s}$ vs. $89.82 \mathrm{~s}$ in $\mathrm{LC}_{10}$ experiment). However, when the concentration of imidacloprid increased to $\mathrm{LC}_{30}$, the dwelling time of E. formosa in the non-infested plant area was significantly longer than the dwelling time spent in $B$. tabaci infested plant area (131.55 s vs. $74.26 \mathrm{~s}$ ). This indicated that when E. formosa adults were exposed to the $\mathrm{LC}_{30}$ of imidacloprid, an opposite preference of host searching behaviour compared to normal occurred; E. formosa could not search for its host as normal when treated with $\mathrm{LC}_{30}$ imidacloprid. When compared with the control, the dwelling time of E. formosa adults in the B. tabaci infested plant area of $\mathrm{LC}_{1}$ treatment had no significant difference, while the dwelling time of $\mathrm{LC}_{10}$ treatment was significantly lower and the $\mathrm{LC}_{30}$ treatment was the lowest. While for the dwelling time in the non-infested plant area, no significant differences were found between the control and $\mathrm{LC}_{1}$ treatment, but the dwelling time of $\mathrm{LC}_{10}$ treatment was significantly longer and the $\mathrm{LC}_{30}$ treatment was the longest (Figure 2). 


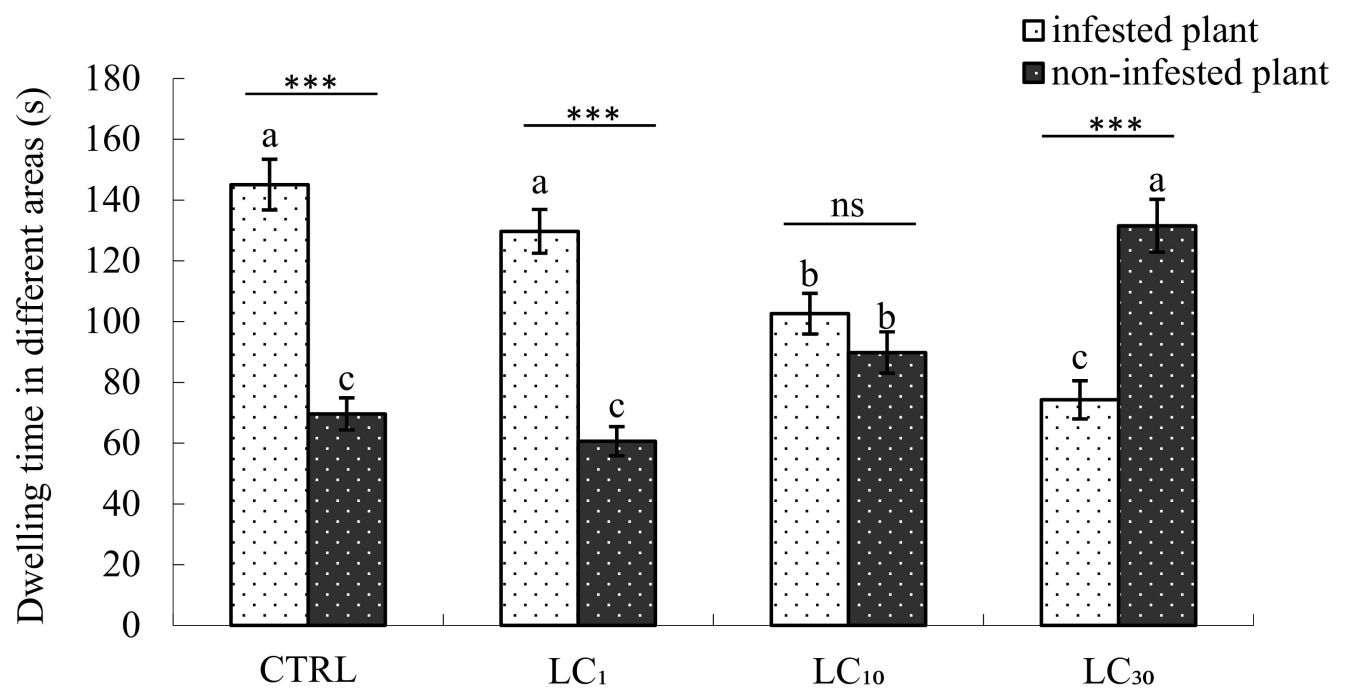

Tested imidacloprid concentrations

Figure 2. Dwelling time of Encarsia formosa in different areas treated with imidacloprid. Note: ${ }^{* * *} p<0.001$ (significantly different between the two groups, $t$-test), ns (not significantly different between the two groups, $t$-test). The same letter over the bars of infested plant or non-infested plant areas indicates no significant differences between the various concentrations (Duncan's multiple range test, $\alpha<0.05)$. The "infested plant area" means cotton plants in the four-armed olfactometer infested with 3rd or 4th instar B. tabaci nymphs, while the "non-infested plants" means healthy cotton plants without whitefly infestation in the four-armed olfactometer.

In the control and $\mathrm{LC}_{1}$ treatment of abamectin, the frequencies that $E$. formosa entered into the B. tabaci infested plant areas were relatively higher than the frequencies of entry into the non-infested plant areas (1.93 and 1.83 times vs. 1.37 and 1.43 times respectively), whereas in the $\mathrm{LC}_{10}$ and $\mathrm{LC}_{30}$ treatments, the frequencies that $E$. formosa entered into the $B$. tabaci infested plant areas were less than that of entering into non-infested plant areas, but there was no significant differences between the two concentration treatments (1.23 and 1.10 times in B. tabaci infested plant area vs. 1.33 and 1.17 times in non-infested plant area). When compared with the control, the frequency that $E$. formosa entered into the $B$. tabaci infested plant area of $\mathrm{LC}_{1}$ treatment had no significant difference, while the frequencies of $\mathrm{LC}_{10}$ and $\mathrm{LC}_{30}$ treatments were significantly lower. However, for the frequencies of entering into the non-infested plant area, no significant differences were found between the control and $\mathrm{LC}_{1}, \mathrm{LC}_{10}$, and $\mathrm{LC}_{30}$ treatments (Figure 3). 


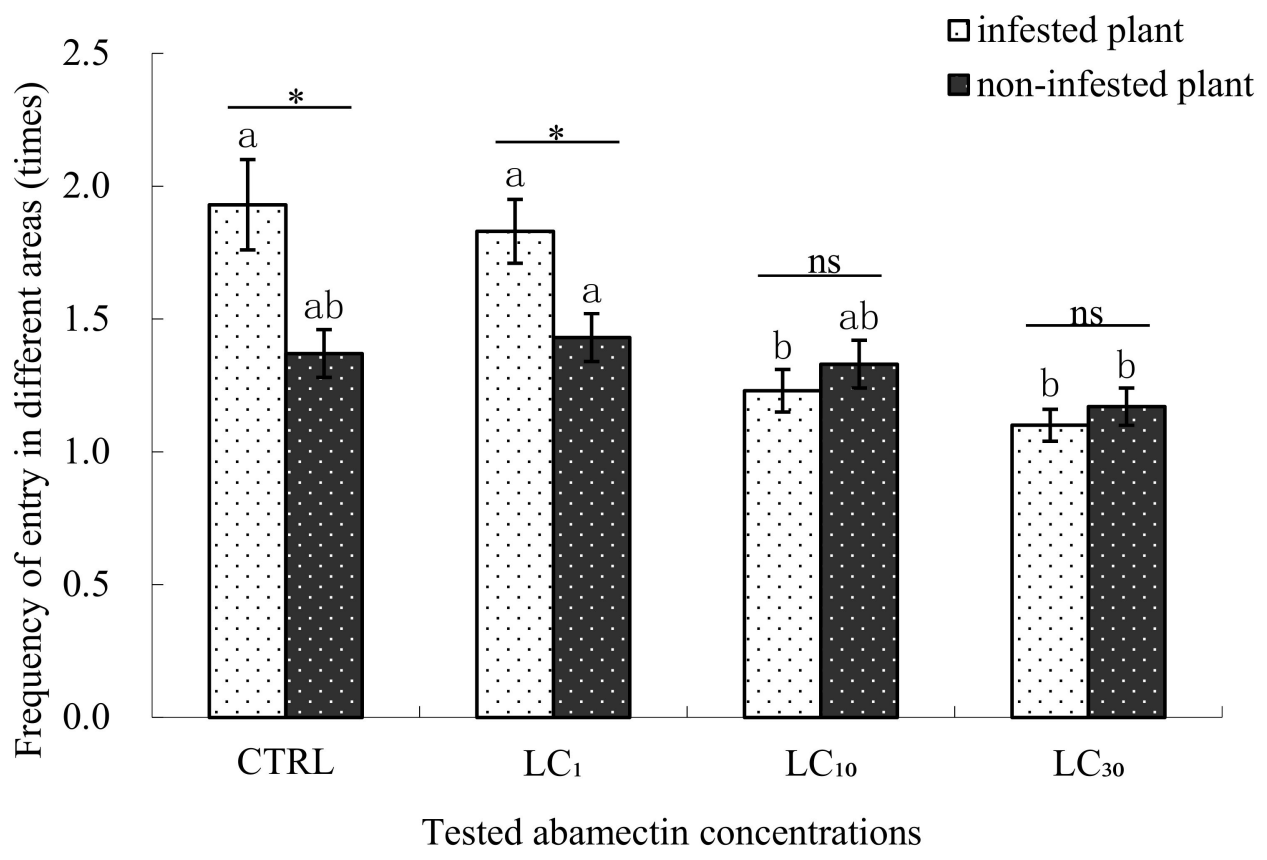

Figure 3. The frequency of Encarsia formosa entering different areas when treated with abamectin. Note: * $p<0.05$ (significantly different between the two groups, $t$-test), ns (not significantly different between the two groups, $t$-test). The same letter over the bars of infested plant or non-infested plant areas indicates no significant differences between the various concentrations (Duncan's multiple range test, $\alpha<0.05)$. The "infested plant area" means cotton plants in the four-armed olfactometer infested with 3rd or 4th instar B. tabaci nymphs, while the "non-infested plants" means healthy cotton plants without whitefly infestation in the four-armed olfactometer.

When treated with $\mathrm{LC}_{1}$, and $\mathrm{LC}_{10}$ concentrations of imidacloprid, the frequencies that $E$. formosa entered into the $B$. tabaci infested plant areas were only a little more than that of entering into the non-infested plant areas (1.33 and 1.10 times vs. 1.23 and 1.07 times respectively), while in the $\mathrm{LC}_{30}$ concentration test, the situation has reversed, the frequency that $E$. formosa entered into the $B$. tabaci infested plant areas were only a little less than that of entering into the non-infested plant areas (1.07 times vs. 1.13 times), but there was no significant differences between the entering frequencies in the $\mathrm{LC}_{1}, \mathrm{LC}_{10}$ and $\mathrm{LC}_{30}$ concentration experiments. Similarly, the frequencies that $E$. formosa entered into the $B$. tabaci infested plant area of $\mathrm{LC}_{1}, \mathrm{LC}_{10}$, and $\mathrm{LC}_{30}$ treatments were significantly less than the frequency of the control. For the frequencies of entering into the non-infested plant areas, no significant differences were found between the control and $\mathrm{LC}_{1}$ treatment but the $\mathrm{LC}_{10}$ and $\mathrm{LC}_{30}$ treatments were significantly less than the control (Figure 4). 


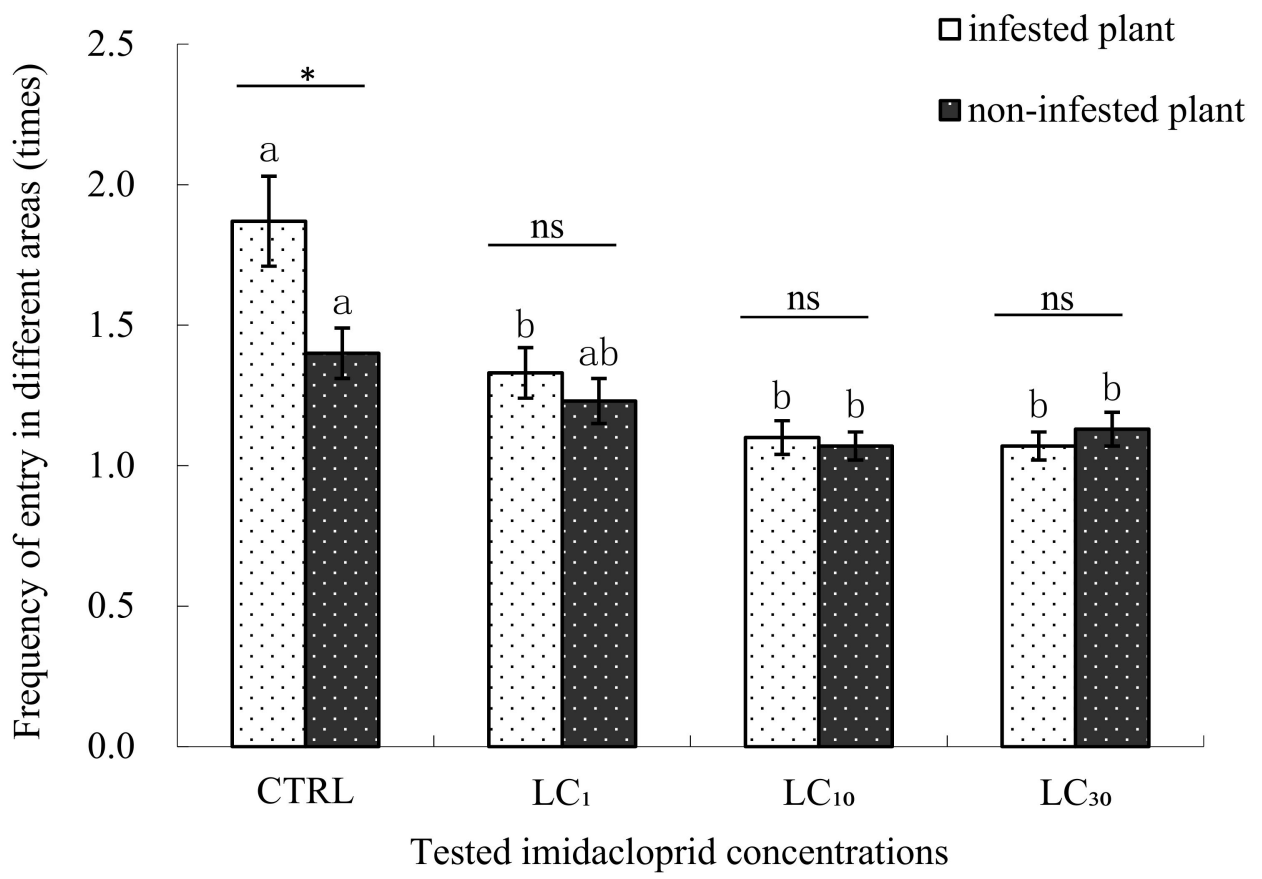

Figure 4. The frequency of Encarsia formosa entering different areas when treated with imidacloprid. Note: ${ }^{*} p<0.05$ (significantly different between the two groups, $t$-test), ns (not significantly different between the two groups, $t$-test). The same letter over the bars of infested plant or non-infested plant areas indicates no significant differences between the various concentrations (Duncan's multiple range test, $\alpha<0.05)$. The "infested plant area" means cotton plants in the four-armed olfactometer infested with 3rd or 4th instar B. tabaci nymphs, while the "non-infested plants" means healthy cotton plants without whitefly infestation in the four-armed olfactometer.

\section{Discussion}

This current research has shown that abamectin has a high toxicity risk against $E$. formosa. This is consistent with the results of Bacci et al. [10], who reported high insecticidal toxicity of abamectin to adults of Encarsia sp. (Hymenoptera: Aphelinidae). Abamectin has also been found to be highly toxic against the adults of other parasitoid wasps, such as Trichogramma chilonis Ishii (Hymenoptera: Trichogrammatidae), Bracon nigricans Szépligeti (Hymenoptera: Braconidae) and Aphidius gifuensis (Ashmead) (Hymenoptera: Braconidae) [24,32,33]. However, results of some other studies differ with those of the present study, for example, abamectin was considered harmless to Agenia spiscitricola Longvinovskaya (Hymenoptera: Encyrtidae) [38], slightly to moderately toxic to Trichogramma japonicum Ahmead (Homenoptera: Trichogrammatidae) [29], and moderately harmful to Aphytis melinus DeBach (Hymenoptera: Aphelinidae) [39]. We suggest that the different conclusions regarding the toxicity may be due to different experimental methods (e.g., insecticide residues on leaves and hosts surfaces in some other experiments but on glass surfaces in our experiments; exposure durations in their experiments were $1 \mathrm{~h}, 24 \mathrm{~h}, 3 \mathrm{~d}$, but varied in 12, 24, 48, 72, and $96 \mathrm{~h}$ in our experiments; the ages of the insects used for experiments in their researches were $24-48 \mathrm{~h}$ old, or $<48 \mathrm{~h}$ old, or $<3 \mathrm{~d}$ old, but $<24 \mathrm{~h}$ old in our research.) and the parasitoid species investigated.

Results in the current study indicated a medium toxicity risk of imidacloprid to E. formosa, and this is similar to the study of Prabhaker et al. [40] with the same insecticide and parasitoid. However, there are also studies that revealed a more severe toxicity of imidacloprid to several species of parasitoids, including Encarsia sp. [10], Encarsia inaron (Walker) (Hymenoptera: Aphelinidae) [30], Eretmocerus mundus Mercet (Hymenoptera: Aphelinidae) [31], Eretmocerus eremicus Rose and Zolnerowich (Hymenoptera: Aphelinidae), A. melinus, Gonatocerus ashmeadi Girault (Hymenoptera: Mymaridae) [40] and Trichogramma cacoeciae Marchal (Hymenoptera: Trichogrammatidae) [41]. These 
different conclusions may again be also due to the experimental methods, insecticide concentrations and the parasitoid species investigated as we mentioned above.

While previous studies investigated the toxicity of insecticides on adults of E. formosa without any concern of their age, the current study investigated this biological factor with abamectin and imidacloprid following E. formosa emergence. It was found that these two insecticides had different risk levels against $E$. formosa adults, in particular abamectin has a high toxicity risk while imidacloprid has a medium toxicity risk.

In the current study, we investigated the toxicity of abamectin and imidacloprid to the pre-pupa and pupa of E. formosa. Here we obtained similar results to the toxicity to the adults: a high toxicity risk of abamectin and a medium toxicity risk of imidacloprid. Harmful effects of abamectin have also been found on the mummy stage of $A$. gifuensis but the mortalities observed were much fewer than when against the adult stage [33]. Mahdavi et al. [22] classified abamectin as slightly harmful when pre-imaginal stages of Habrobracon hebetor Say (Hymenoptera: Braconidae) were treated with this chemical. For imidacloprid, Saber [41] found lower toxicity to the larvae, pre-pupae and pupae of T. cacoeciae when compared to the adults. The higher toxicity of insecticides to adults than to pre-pupae or pupae of parasitoids is probably due to immature parasitoids developing within host bodies are protected from many pesticides $[23,33,42,43]$. The mechanism of contrary findings between this study and previous studies requires further investigation, but the sensitivity of different parasitoid species to a given insecticide maybe one of the biological factors playing a role [22,44]. Different methods employed in experiments for adults (insecticide on glass surface in our experiments) and pre-pupae and pupae (insecticide on leaf surface in our experiments) may also lead to differences in a parasitoid's response to an insecticide. The side effects of these two insecticides on natural enemies might be waved in field comparing to that in the laboratory. For example, when applied in the field, abamectin was recorded to be not harmful to parasitoids on Java potato [45], but imidacloprid has negative effects on the parasitism and population dynamics of aphid parasitoids [46,47].

Sublethal concentrations of pesticides may not only affect the physiological traits of a natural enemy (e.g., lifespan, growth and reproduction), but can also interfere its behaviour in regards to host searching, learning, and communication [20,23,35]. In this study, sublethal concentrations of both insecticides (abamectin and imidacloprid) caused a distinct negative influence on the efficiency of the parasitoids' host searching ability. Similar results were found for Neochrysocharis formosa (Westwood) (Hymenoptera: Eulophidae) [48] and Anagrus nilaparvatae (Pang et Wang) (Hymenoptera: Mymaridae) [49] when the parasitoids were treated with sublethal concentrations of imidacloprid. Bethke and Redak [50] found lower parasitism of E. formosa on Bemisia argentifolii Bellows and Perring (Hemiptera: Aleyrodidae) when the pest nymphs were treated with imidacloprid. When treated with an $\mathrm{LC}_{30}$ of abamectin, the host searching behaviour of $E$. formosa was significantly affected, but it was less influenced when treated with the $\mathrm{LC}_{10}$ concentration, while for $\mathrm{LC}_{1}$ treatment it was slightly affected. The behaviour was also remarkably forced into a reverse trend when treated with $\mathrm{LC}_{1}$, $\mathrm{LC}_{10}$ and $\mathrm{LC}_{30}$ of imidacloprid. The reduction of host searching behaviour in our results can lead to both decreased oviposition and parasitism rate. Pesticides can lead to a reduction in the parasitoids' sensitivity and response to volatiles from hosts or pest-infested plants [49]. This may be because of the obstruction or destruction of perception and response to related pheromones [51,52], so the searching efficiency is reduced.

\section{Conclusions}

In summary, our results have indicated that abamectin and imidacloprid both have high or medium acute toxicity against $E$. formosa and negative sublethal effects on its host searching behaviour. Therefore, abamectin and imidacloprid should be more cautiously used within IPM programmes against $B$. tabaci as they have been shown to reduce the effectiveness of E. formosa. In addition, the residue of these insecticides within the environment (on plants in the soil), as well as other non-target effects combining biotic and abiotic factors to this parasitoid, should be further studied [53]. 
Discrete precautionary measures should be taken before applying these insecticides or, indeed, some other effective and sustainable methods. Furthermore, products should be evaluated and applied within IPM programmes against B. tabaci in their place.

Author Contributions: Conceptualization, B.-L.Q. and X.-S.C.; Methodology, Z.H. and Q.G.; Formal Analysis, Z.H. and Q.G.; Investigation, Y.L. and L.W.; Writing-Original Draft Preparation, Z.H. and Y.L.; Writing-Review \& Editing, B.-L.Q. and S.A.; Funding Acquisition, B.-L.Q.

Funding: This research was funded by the National Key Research and Development Programme of China (2017YFD0200400), the Guangdong Science and Technology Innovation Leading Talent Program (2016TX03N273), the Science and Technology Program of Guangzhou (201804020070), and the Guangdong Province Universities and Colleges Pearl River Scholar Funded Scheme (2014-19) to B.-L.Q.

Acknowledgments: We thank Andrew G S Cuthbertson (Defra, UK) for his critical comments on an early draft of the manuscript.

Conflicts of Interest: The authors declare no conflicts of interest. The funders had no role in the design of the study; in the collection, analyses, or interpretation of data; in the writing of the manuscript, and in the decision to publish the results.

\section{References}

1. Brown, J.K.; Frohlich, D.R.; Rosell, R.C. The sweetpotato or silverleaf whiteflies: Biotypes of Bemisia tabaci oraspeciesco complex. Annu. Rev. Entomol. 1995, 40, 511-534. [CrossRef]

2. De Barro, P.J.; Liu, S.S.; Boykin, L.M.; Dinsdale, A.B. Bemisia tabaci: A statement of species status. Annu. Rev. Entomol. 2011, 56, 1-19. [CrossRef] [PubMed]

3. Berlinger, M.J. Host plant resistance to Bemisia tabaci. Agric. Ecosyst. Environ. 1986, 17, 69-82. [CrossRef]

4. Jones, D.R. Plant viruses transmitted by whiteflies. Eur. J. Plant Pathol. 2003, 109, 195-219. [CrossRef]

5. Qiu, B.L.; Dang, F.; Li, S.J.; Ahmed, M.Z.; Jin, F.L.; Ren, S.X.; Cuthbertson, A.G.S. Comparison of biological parameters between the invasive B biotype and a new defined $\mathrm{Cv}$ biotype of Bemisia tabaci (Hemiptera: Aleyrodidae) in China. J. Pest Sci. 2011, 84, 419-427. [CrossRef]

6. Su, Q.; Pan, H.P.; Liu, B.M.; Chu, D.; Xie, W.; Wu, Q.J.; Wang, S.L.; Xu, B.Y.; Zhang, Y.J. Insect symbiont facilitates vector acquisition, retention, and transmission of plant virus. Sci. Rep. 2013, 3, srep01367. [CrossRef] [PubMed]

7. Cuthbertson, A.G.S.; Buxton, J.H.; Blackburn, L.F.; Mathers, J.J.; Robinson, K.A.; Powell, M.E.; Fleming, D.A.; Bell, H.A. Eradicating Bemisia tabaci Q biotype on poinsettia plants in the UK. Crop Prot. 2012, 42, 42-48. [CrossRef]

8. Basit, M.; Saeed, S.; Ahmad, M.; Sayyed, A.H. Can resistance in Bemisia tabaci (Homoptera: Aleyrodidae) be overcome with mixtures of neonicotinoids and insect growth regulators? Crop Prot. 2013, 44, 135-141. [CrossRef]

9. Gerling, D.; Alomar, Ò.; Arnò, J. Biological control of Bemisia tabaci using predators and parasitoids. Crop Prot. 2001, 20, 779-799. [CrossRef]

10. Bacci, L.; Crespo, A.L.B.; Galvan, T.L.; Pereira, E.J.G.; Picanco, M.C.; Silva, G.A.; Chediak, M. Toxicity of insecticides to the sweetpotato whitefly (Hemiptera: Aleyrodidae) and its natural enemies. Pest Manag. Sci. 2007, 63, 699-706. [CrossRef] [PubMed]

11. Li, S.J.; Xue, X.; Ahmed, M.Z.; Ren, S.X.; Du, Y.Z.; Wu, J.H.; Cuthbertson, A.G.S.; Qiu, B.L. Host plants and natural enemies of Bemisia tabaci (Homoptera: Aleyrodidae) in China. Insect Sci. 2011, 18, 101-120. [CrossRef]

12. Van Lenteren, J.C.; Van Roermund, H.J.W.; Sutterlin, S. Biological control of greenhouse whitefly (Trialeurodes vaporariorum) with the parasitoid Encarsia formosa: How does it work? Biol. Control 1996, 6, 1-10. [CrossRef]

13. Van Lenteren, J.C. A greenhouse without pesticides: Fact or fantasy. Crop Prot. 2000, 19, 375-384. [CrossRef]

14. Sugiyama, K.; Katayama, H.; Saito, T. Effect of insecticides on the mortalities of three whitefly parasitoid species, Eretmocerus mundus, Eretmocerus eremicus and Encarsia formosa (Hymenoptera: Aphelinidae). Appl. Entomol. Zool. 2011, 46, 311-317. [CrossRef]

15. Cuthbertson, A.G.S.; Murchie, A.K. European red spider mite-An environmental consequence of persistent chemical pesticide application. Int. J. Environ. Sci. Technol. 2005, 2, 287-290. [CrossRef] 
16. Prabhaker, N.; Morse, J.G.; Castle, S.J.; Naranjo, S.E.; Henneberry, T.J.; Toscano, N.C. Toxicity of seven foliar insecticides to four insect parasitoids attacking citrus and cotton pests. J. Econ. Entomol. 2007, 100, 1053-1061. [CrossRef] [PubMed]

17. Bueno, A.F.; Batistela, M.J.; Bueno, R.C.O.F.; Franca-Neto, J.B.; Nishikawa, M.A.N.; Filho, A.L. Effects of integrated pest management, biological control and prophylactic use of insecticides on the management and sustainability of soybean. Crop Prot. 2011, 30, 937-945. [CrossRef]

18. Biondi, A.; Desneux, N.; Siscaro, G.; Zappalà, L. Using organic-certified rather than synthetic pesticides may not be safer for biological control agents: Selectivity and side effects of 14 pesticides on the predator Orius laevigatus. Chemosphere 2012, 87, 803-812. [CrossRef] [PubMed]

19. Cuthbertson, A.G.S.; Murchie, A.K. The environmental impact of an orchard winter wash and early season pesticide applications on both a beneficial and a pest mite species in Bramley apple orchards. Int. J. Environ. Sci. Technol. 2006, 3, 333-339. [CrossRef]

20. Cloyd, R.A.; Bethke, J.A. Impact of neonicotinoid insecticides on natural enemies in greenhouse and interiorscape environments. Pest Manag. Sci. 2011, 67, 3-9. [CrossRef] [PubMed]

21. Walthall, W.K.; Stark, J.D. A comparison of acute mortality and population growth rate as endpoints of toxicological effect. Ecotoxicol. Environ. Saf. 1997, 37, 45-52. [CrossRef] [PubMed]

22. Mahdavi, V.; Saber, M.; Rafiee, D.H.; Mehrvar, A. Comparative study of the population level effects of carbaryl and abamectin on larval ectoparasitoid Habrobracon hebetor Say (Hymenoptera: Braconidae). BioControl 2011, 56, 823-830. [CrossRef]

23. Desneux, N.; Decourtye, A.; Delpuech, J.M. The sublethal effects of pesticides on beneficial arthropods. Annu. Rev. Entomol. 2007, 52, 81-106. [CrossRef] [PubMed]

24. Wang, D.S.; He, Y.R.; Guo, X.L.; Luo, Y.L. Acute toxicities and sublethal effects of some conventional insecticides on Trichogramma chilonis (Hymenoptera: Trichogrammatidae). J. Econ. Entomol. 2012, 105, 1157-1163. [CrossRef] [PubMed]

25. Moura, R.; Garcia, P.; Cabral, S.; Soares, A.O. Does pirimicarb affect the voracity of the euriphagous predator, Coccinella undecimpunctata L. (Coleoptera: Coccinellidae)? Biol. Control 2006, 38, 363-368. [CrossRef]

26. Palumbo, J.C.; Horowitzb, A.R.; Prabhaker, N. Insecticidal control and resistance management for Bemisia tabaci. Crop Prot. 2001, 20, 739-765. [CrossRef]

27. Tomizawa, M.; Casida, J.E. Selective toxicity of neonicotinoids attributable to specificity of insect and mammalian nicotinic receptors. Annu. Rev. Entomol. 2003, 48, 339-364. [CrossRef] [PubMed]

28. Jeschke, P.; Nauen, R. Neonicotinoids-From zero to hero in insecticide chemistry. Pest Manag. Sci. 2008, 64, 1084-1098. [CrossRef] [PubMed]

29. Zhao, X.P.; Wu, C.X.; Wang, Y.H.; Cang, T.; Chen, L.P.; Yu, R.X.; Wang, Q. Assessment of toxicity risk of insecticides used in rice ecosystem on Trichogramma japonicum, an egg parasitoid of rice lepidopterans. J. Econ. Entomol. 2012, 105, 92-101. [CrossRef] [PubMed]

30. Sohrabi, F.; Shishehbor, P.; Saber, M.; Mosaddegh, M.S. Lethal and sublethal effects of buprofezin and imidacloprid on the whitefly parasitoid Encarsia inaron (Hymenoptera: Aphelinidae). Crop Prot. 2012, 32, 83-89. [CrossRef]

31. Sohrabi, F.; Shishehbor, P.; Saber, M.; Mosaddegh, M.S. Lethal and sublethal effects of imidacloprid and buprofezin on the sweetpotato whitefly parasitoid Eretmocerus mundus (Hymenoptera: Aphelinidae). Crop Prot. 2013, 45, 98-103. [CrossRef]

32. Biondi, A.; Zappala, L.; Stark, J.D.; Desneux, N. Do biopesticides affect the demographic traits of a parasitoid wasp and its biocontrol services through sublethal effects? PLoS ONE 2013, 8, e76548. [CrossRef] [PubMed]

33. Ohta, I.; Takeda, M. Acute toxicities of 42 pesticides used for green peppers to an aphid parasitoid, Aphidius gifuensis (Hymenoptera: Braconidae), in adult and mummy stages. Appl. Entomol. Zool. 2015, 50, $207-212$. [CrossRef]

34. Chitgar, M.G.; Ghadamyari, M. Effects of Amitraz on the parasitoid Encarsia formosa (Gahan) (Hymenoptera: Aphelinidae) for Control of Trialeurodes vaporariorum Westwood (Homoptera: Aleyrodidae): IOBC Methods. J. Entomol. Res. Soc. 2012, 14, 61-69. 
35. Desneux, N.; Pham-Delègue, M.H.; Kaiser, L. Effects of sub-lethal and lethal doses of lambda-cyhalothrin on oviposition experience and host-searching behaviour of a parasitic wasp, Aphidius ervi. Pest Manag. Sci. 2004, 60, 381-389. [CrossRef] [PubMed]

36. Cuthbertson, A.G.S.; Blackburn, L.F.; Northing, P.; Luo, W.; Cannon, R.J.C.; Walters, K.F.A. Leaf dipping as an environmental screening measure to test chemical efficacy against Bemisia tabaci on poinsettia plants. Int. J. Environ. Sci. Technol. 2009, 6, 347-352. [CrossRef]

37. General Administration of Quality Supervision, Inspection and Quarantine of the People's Republic of China and Standardization Administration of the People's Republic of China. Test Guidelines on Environmental Safety Assessment for Chemical Pesticides-Part 17: Trichogramma Acute Toxicity Test; China Zhijian Publishing House \& Standards Press of China: Beijing, China, 2014; pp. 1-12.

38. De Morais, M.R.; Zanardi, O.Z.; Rugno, G.R.; Yamamoto, P.T. Impact of five insecticides used to control citrus pests on the parasitoid Ageniaspis citricola Longvinovskaya (Hymenoptera: Encyrtidae). Ecotoxicology 2016, 25, 1011-1020. [CrossRef] [PubMed]

39. Vanaclocha, P.; Vidal-Quist, C.; Oheix, S.; Monton, H.; Planes, L.; Catalan, J.; Tena, A.; Verdu, M.J.; Urbaneja, A. Acute toxicity in laboratory tests of fresh and aged residues of pesticides used in citrus on the parasitoid Aphytis melinus. J. Pest Sci. 2013, 86, 329-336. [CrossRef]

40. Prabhaker, N.; Castle, S.J.; Naranjo, S.E.; Toscano, N.C.; Morse, J.G. Compatibility of two systemic neonicotinoids, imidacloprid and thiamethoxam, with various natural enemies of agricultural pests. J. Econ. Entomol. 2011, 104, 773-781. [CrossRef] [PubMed]

41. Saber, M. Acute and population level toxicity of imidacloprid and fenpyroximate on an important egg parasitoid, Trichogramma cacoeciae (Hymenoptera: Trichogrammatidae). Ecotoxicology 2011, 20, 1476-1484. [CrossRef] [PubMed]

42. Suh, C.P.C.; Orr, D.B.; van Duyn, J.W. Effect of insecticides on Trichogramma exiguum (Trichogrammatidae: Hymenoptera) preimaginal development and adult survival. J. Econ. Entomol. 2000, 93, 577-583. [CrossRef] [PubMed]

43. Preetha, G.; Stanley, J.; Suresh, S.; Kuttalam, S.; Samiyappan, R. Toxicity of selected insecticides to Trichogramma chilonis: Assessing their safety in the rice ecosystem. Phytoparasitica 2009, 37, $209-215$. [CrossRef]

44. Wang, H.Y.; Yang, Y.; Su, J.Y.; Shen, J.L.; Gao, C.F.; Zhu, Y.C. Assessment of the impact of insecticides on Anagrus nilaparvatae (Pang et Wang) (Hymenoptera: Mymanidae), an egg parasitoid of the rice planthopper, Nilaparvata lugens (Hemiptera: Delphacidae). Crop Prot. 2008, 27, 514-522. [CrossRef]

45. Hidrayani; Purnomo; Rauf, A.; Ridland, P.M.; Hoffmann, A.A. Pesticide applications on Java potato fields are ineffective in controlling leafminers, and have antagonistic effects on natural enemies of leafminers. Int. J. Pest Manag. 2005, 51, 181-187. [CrossRef]

46. Mohammed, A.A.H.; Desneux, N.; Fan, Y.J.; Han, P.; Ali, A.; Song, D.L.; Gao, X.W. Impact of imidacloprid and natural enemies on cereal aphids: Integration or ecosystem service disruption? Entomol. Gen. 2017, 1, 47-61. [CrossRef]

47. Varenhorst, A.J.; O'Neal, M.E. The response of natural enemies to selective insecticides applied to soybean. Environ. Entomol. 2012, 41, 1565-1574. [CrossRef] [PubMed]

48. Tran, D.H.; Takagi, M.; Takasu, K. Effects of selective insecticides on host searching and oviposition behavior of Neochrysocharis formosa (Westwood) (Hymenoptera: Eulophidae), a larval parasitoid of the American serpentine leafminer. Appl. Entomol. Zool. 2004, 39, 435-441. [CrossRef]

49. Liu, F.; Bao, S.W.; Song, Y.; Lu, H.Y.; Xu, J.X. Effects of imidacloprid on the orientation behavior and parasitizing capacity of Anagrus nilaparvatae, an egg parasitoid of Nilaparvata lugens. BioControl 2010, 55, 473-483. [CrossRef]

50. Bethke, J.A.; Redak, R.A. Effect of imidacloprid on the silverleaf whitefly, Bemisia argentifolii Bellows and Perring (Homoptera: Aleyrodidae), and whitefly parasitism. Ann. Appl. Biol. 1997, 130, 397-407. [CrossRef]

51. Desneux, N.; Rafalimanana, H.; Kaiser, L. Dose-response relationship in lethal and behavioural effects of different insecticides on the parasitic wasp Aphidius ervi. Chemosphere 2004, 54, 619-627. [CrossRef] [PubMed] 
52. Bayram, A.; Salerno, G.; Onofri, A.; Conti, E. Sublethal effects of two pyrethroids on biological parameters and behavioral responses to host cues in the egg parasitoid Telenomus busseolae. Biol. Control 2010, 53, 153-160. [CrossRef]

53. Abbes, K.; Biondi, A.; Kurtulus, A.; Ricupero, M.; Russo, A.; Siscaro, G.; Chermiti, B.; Zappala, L. Combined non-target effects of insecticide and high temperature on the parasitoid Bracon nigricans. PLoS ONE 2015, 10, e0138411. [CrossRef] [PubMed] 